\title{
Modeling Information Technology Competency using Neural Networks
}

\author{
Fadzilah Siraj* \\ School of Computing \\ College of Arts and Sciences \\ University Utara Malaysia
}

\author{
Hashim Asman \\ School of Computing \\ College of Arts and Sciences \\ University Utara Malaysia
}

\author{
Md. Rajib Hasan* \\ School of Computing \\ College of Arts and Sciences \\ University Utara Malaysia
}

\author{
${ }^{*}$ Corresponding Author: \\ CORRESPONDING AUTHOR: For all stages of refereeing and publication including post-publication
}

\begin{abstract}
Neural Network (NN) is one of the most important branches of AI that has been applied to an increasing number of realworld problems of considerable complexity from the financial markets to real estate, medicine and education. The most commonly used is multilayer perceptron with back propagation that is capable of representing non-linear functional mapping between inputs and outputs. In this paper, such a net is used to forecast the information technology competency among teacher trainees in the teaching institutes. The system has been developed as a web-based selfassessment information system that can be used to obtain a model for predicting the information technology competency. The system functions as an instrument that generates questionnaires as well as performing rubric assessment online. The data will be entered online using the web as a medium. This data will be fed into the NNsimulator to obtain a suitable model. Once the model is obtained, it will then be used to predict the information technology competency among the teacher trainees. The data was collected from various teachers' training institutions in Malaysia. The findings indicate that the most suitable forecasting model comprises of eleven input nodes, five hidden nodes and one output node. The performance of the selected model obtained with an accuracy of $99.77 \%$. Hence the results show that the developed system can be used as a tool to assist decisionmaking in education.
\end{abstract}

\section{Keywords}

Modeling, Information Technology Competency, Neural Network, Prediction.

\section{INTRODUCTION}

In recognition of the increasing importance of Information and Communication Technologies (ICT) in the area of teacher education, teachers are recommended to acquire information technology competency (ITC) as they are the driving force in education. In Malaysia, all trainee teachers are required to undertake Teaching and Learning Resource Management course [1]. At the end of the course, the trainee teachers are expected to acquire information technology competency (ITC).

Other countries such as UK [2] and Hong Kong Institute of Education (HKIEd) has continually revised and monitored the changes required within various programs to keep up with the rapidly emerging IT in Education developments and the IT in Education policy documents and reports from the HKSAR Government.
Since the information technology, competency is very important, it is therefore an advantage if the teaching institutions could forecast the trainees' competency prior to their enrolment to Teaching and Learning Resource Management course. The forecasting results could provide some insights and later could be used by the institutions to assist decision-making in education.

$\mathrm{NN}$ is one of the most important branches of $\mathrm{AI}$ that has been applied to an increasing number of real-world problems[3] of considerable complexity from the finance [4] to real estate, medicine and education[5], pattern recognition[6]; [7]; [8]. The most commonly used is multilayer perceptron that is capable of representing non-linear functional mapping between inputs and outputs. These networks can be trained with a powerful and computationally efficient method called back-propagation.

$\mathrm{NN}$ is potentially useful for studying the complex relationship between inputs and outputs of the system[9]. It is proven helpful and able to improve decision making by MBA directors and deans when predicting the students' performance [10]. NN has also been used to measure the student performance assessment and monitoring system within a teaching and learning environment[11].ANN can predict the performance of students during admission to some of the Nigerian Universities due to poor quality of graduates in recent times. The results indicate that ANN is potentially enhancing the effectiveness of a university admission system with an accuracy of $70 \%[12]$.

In this paper, a multilayer perceptron that utilizes back propagation learning is used to forecast the ITC among teacher trainees in the teaching institutes. In information technology era, teachers are recommended to acquire information technology competency (ITC) as they are the driving force in education.

\section{INFORMATION TECHNOLOGY COMPETENCY}

Any decision of ICT literacy must begin with the concept of information literacy. As defined by American Library Association, "To be information literate, a person must be able to recognize when information is needed and have the ability to locate, evaluate and use effectively the needed information" [13]. ITC includes the knowledge of the characteristics, the use of hardware and software, computer system organization structure and its social impact[14]. ITC also refers to integration of intellectual ability with basic concepts and skills with regard to hardware and software 
applications for efficient use of information technology[15]. Based on the ITC definitions, knowledge and skills are two important elements when measuring ITC. Malaysian ITC's framework for teachers was formulated by four domains, namely:

Domain 1: Basic skills in computer operation, running programs, accessing and editing data using the multimedia computer systems.

Domain 2:Communication skills and the ability to solve problems using several available software such as word processing, graphical,database spread sheet, multimedia application, telecommunication, and software application for education management.

Domain 3: Knowledge in social issues, ethical, law, copyright and intellectual property in using computer software and hardware.

Domain 4: Skills in (IT) in teaching such as planning and the ability to create new teaching materials by integrating several software and IT tools to make the teaching process more effective and interactive.

The main emphasis of ITC for trainee teachers in Malaysia is on basic skills in using IT and computer literacy for teaching and learning purposes (Ministry of Education, Malaysia, 2001). The scope of the knowledge and IT skills for educational institution for trainee teachers in Malaysia includes (Table 2):

Table 2.Knowledge and IT skills for trainee teachers

\begin{tabular}{|c|c|c|c|}
\hline No & Name & No & Name \\
\hline $\mathbf{i}$ & $\begin{array}{c}\text { Introduction to } \\
\text { Information } \\
\text { Technology }\end{array}$ & $\mathbf{v i}$ & Database \\
\hline ii & $\begin{array}{c}\text { Word processing } \\
\text { Internet Access and } \\
\text { Networking }\end{array}$ & $\mathbf{v i i}$ & $\begin{array}{c}\text { Computer Assistant } \\
\text { for Teaching and } \\
\text { Learning }\end{array}$ \\
\hline iii & Spread Sheet & viii & $\begin{array}{c}\text { Multimedia in } \\
\text { Education }\end{array}$ \\
\hline iv & $\begin{array}{c}\text { Electronic } \\
\text { Presentation }\end{array}$ & $\mathbf{i x}$ & $\begin{array}{c}\text { Integration of } \\
\text { Application }\end{array}$ \\
\hline v & $\begin{array}{c}\text { Information } \\
\text { Technology } \\
\text { Management in } \\
\text { TeachingLearning }\end{array}$ & & \\
\hline
\end{tabular}

Since the ITC is necessary in teaching and learning, it is important to ensure that the trainee teachers among teaching institutions obtain a common ITC standard. Due to this reason, NeuroCite has been developed as a tool for an educationist to forecast such a competency.

\subsection{NEURAL}

\section{NETWORKCOMPETENCY}

The comparative performance between $\mathrm{NN}$ and other predictor models has shown that NN outperform them, particularly the logistic regression. For example, the lift chart shown in Figure 1 indicates that between 10-90\% percentiles, both NN and Decision Tree obtained the same accuracy. However, between $90-100 \%$ percentiles, NN degrades slowly compared to Decision Tree. Hence, NN is the better model among the three [16].

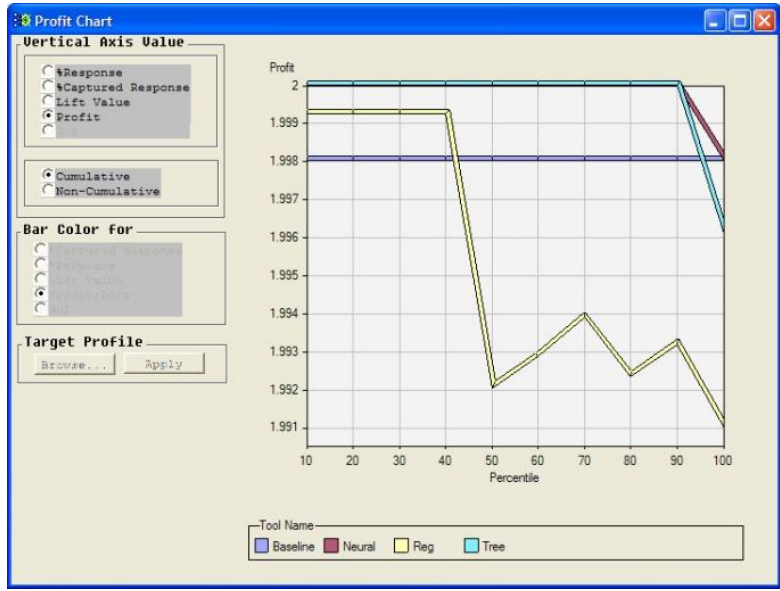

Fig 1: The accuracy of NN and Decision Tree

The findings from the experiments conducted by [17] exhibit that the significant correlations of QFD with customer voices help to explain the relationship between attributes. The study also indicates that $\mathrm{NN}$ forecasting model has been established with 12.30 percent misclassification error in determining the customer voices based on QFD is lower than Logistic regression accuracy. Other study conducted by[4], [18]and [3]also confirm that $\mathrm{NN}$ performance outperform logistic regression.

For brevity, Table 1 exhibits NN parameters that produce the highest percentage of accuracy for Wisconsin Breast Cancer, and German Credit data set using all variables as well as selected variables in the experiments [3]

Table 1.The summary of NN experimental results using As_Is representation

\begin{tabular}{|l|c|c|c|}
\hline $\begin{array}{l}\text { Neural } \\
\text { Network }\end{array}$ & $\begin{array}{c}\text { Wisconsin } \\
\text { Breast } \\
\text { Cancer }\end{array}$ & $\begin{array}{c}\text { German } \\
\text { credit } \\
\text { using all } \\
\text { variables }\end{array}$ & $\begin{array}{c}\text { German } \\
\text { credit using } \\
\text { selected } \\
\text { variables }\end{array}$ \\
\hline $\begin{array}{l}\text { Percentage of } \\
\text { Accuracy }\end{array}$ & $98.57 \%$ & $80.00 \%$ & $79.00 \%$ \\
\hline Input units & 9 & 20 & 12 \\
\hline Hidden units & 2 & 6 & 20 \\
\hline $\begin{array}{l}\text { Learning } \\
\text { rate }\end{array}$ & 0.1 & 0.6 & 0.6 \\
\hline $\begin{array}{l}\text { Momentum } \\
\text { rate }\end{array}$ & 0.8 & 0.1 & 0.1 \\
\hline $\begin{array}{l}\text { Number of } \\
\text { epoch }\end{array}$ & 100 & 100 & 100 \\
\hline
\end{tabular}

German Credit dataset was tested with $\mathrm{NN}$; the highest percentage accuracy was obtained using As_Is representation (80\%), followed by Standard Deviation Normalization (79\%) Min Max Normalization (78\%) and Thermometer (78\%) representation[3]. The regression results show similar patterns with results illustrated in Figure 2. In other words, the data 
representation techniques, namely Thermometer (77.4\%) and Flag $(77.4 \%)$ representations produce the highest and second highest percentage of accuracy for selected variables of German Credit[3].

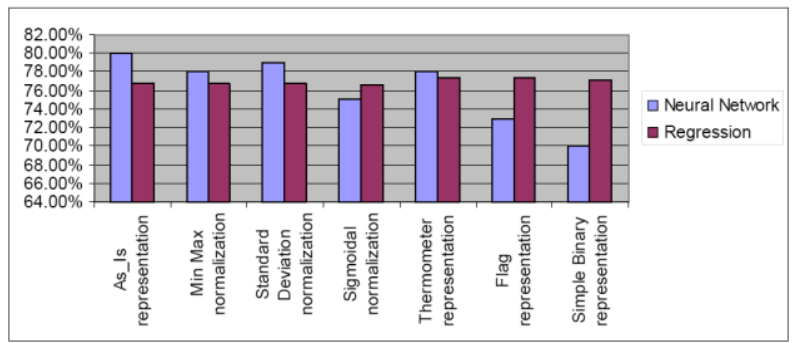

Fig 2:German Credit Selected Variables accuracy for NN and Regression

\section{NEUROCITE SYSTEM}

NeuroCite is a Web-based information system whose acronym represents $\mathrm{NN}$ for Computer and Information Technology Competency. The system has been developed as a web-based self-assessment information system that can be used to obtain a model for predicting the information technology competency (see also [19]; [20]). The system functions as an instrument that generates questionnaires as well as performing rubric assessment online. The data are entered online using the web as a medium, and later fed into $\mathrm{NN}$ simulator to build an ITC forecasting model. Once the model is obtained, it will be used to predict the ITC of the trainee teachers. In this study, respondents are from various teachers' training institutions in Malaysia.

\subsection{Data Preparation}

The data for NeuroCite has been collected from the respondents using the questionnaires that comprise of two parts. In the first part, the respondents' demographic information is collected and becomes part of input parameters for the forecasting model.

The first part deals with the respondents' background that will be used as part of input parameters for the forecasting model. The selection of predicting variables can be based on the experts' knowledge in the research domain[21]. Hence in this study, the respondent demographic information is listed as follows (Table 3):

Table 3.Respondent's information

\begin{tabular}{|c|c|c|c|}
\hline Variable & Item & Variable & Item \\
\hline $\mathbf{I}_{\mathbf{1}}$ & Sex & $\mathbf{I}_{\mathbf{6}}$ & $\begin{array}{c}\text { Personal } \\
\text { Computer at } \\
\text { Home }\end{array}$ \\
\hline $\mathbf{I}_{\mathbf{2}}$ & Race & $\mathbf{I}_{\mathbf{7}}$ & $\begin{array}{c}\text { Access to } \\
\text { Internet at Home }\end{array}$ \\
\hline $\mathbf{I}_{\mathbf{3}}$ & Type of School & $\mathbf{I}_{\mathbf{8}}$ & $\begin{array}{c}\text { Computer } \\
\text { Training }\end{array}$ \\
\hline $\mathbf{I}_{\mathbf{4}}$ & $\begin{array}{c}\text { Level of } \\
\text { Education }\end{array}$ & $\mathbf{I}_{\mathbf{9}}$ & $\begin{array}{c}\text { Programmed } \\
\text { Study }\end{array}$ \\
\hline $\mathbf{I}_{\mathbf{5}}$ & $\begin{array}{c}\text { Grade for } \\
\text { Modern } \\
\text { Mathematics }\end{array}$ & $\mathbf{I}_{\mathbf{1 0}}$ & $\begin{array}{c}\text { Semester of } \\
\text { Study }\end{array}$ \\
\hline
\end{tabular}

The demographic information of the respondents has been classified into three, namely the information related to school, experience and the teaching institution.

The second part of the questionnaires consists of selfevaluation items on ITC information. That will be used as part of input parameters for the forecasting model[22]; [23] ; [23]. These items were constructed based on the Association for Educational Communication and Technology (AECT) and the International Society for Technology in Education (ISTE). The scores were evaluated and adopted from Microsoft Office Rubrics [24] The self-evaluation part consists of 12 items that have been classified into 4 categories:

- Basic competency in file management using the current operating system.

- Competent in using application packages in Microsoft Office.

- Competent in using the Internet for communication and searching information.

- Level of knowledge with regard to ethics in using the computer software

Rubric scales were used to represent the scores in ITC selfevaluation. The scores and their corresponding weights were used in this study since the score's range is able to distinguish the level of ITC effectively compared to the scores without the weights. Once the training of $\mathrm{NN}$ is completed, $\mathrm{NN}$ model will be obtained. To test the system, respondents from the teaching institutions in the North Zone of Malaysia were requested to answer the questionnaires. As a result, NN model for forecasting the ICT is obtained and the schematic diagram is illustrated in Figure 3.

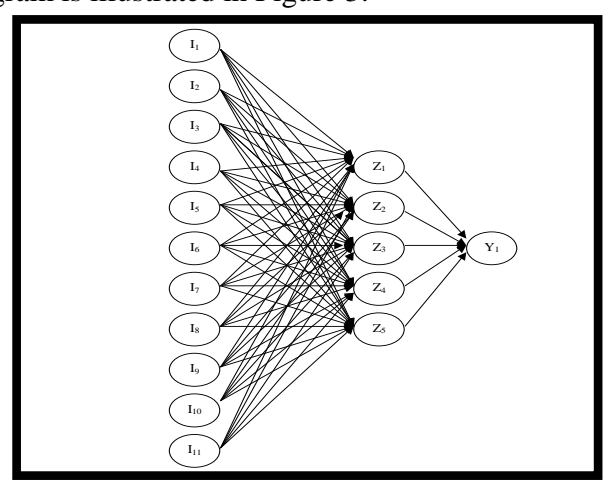

Fig 3: NN Model for Forecasting ITC

\subsection{System Development}

$\mathrm{NN}$ approach has been used in this system as an engine to predict and evaluate the performance level of ITC among trainees in the teaching institution. NeuroCite system has five main integrated modules, viz.:

Self-Evaluation Editor Module: is used to develop the research item and evaluation item.

$\square$ Self-Evaluation Module: is used to collect research item and evaluation item on-line.

$\square$ Pattern Analysis Module: is used to pre-process data prior to $\mathrm{NN}$ training.

$\square$ Backpropagation Simulator Module: Backpropagation algorithm is used for training and testing purposes. The prediction model will be obtained. 
Neural Predicting Module: uses the results obtain from Backpropagation Simulator Module to predict the ICT level of the trainee teachers.

\subsubsection{System Development}

This module is provided so that the lecturers can construct questionnaires items online according to the specified format (Figure 4). In addition, the lecturers could also access available questionnaires from the server.

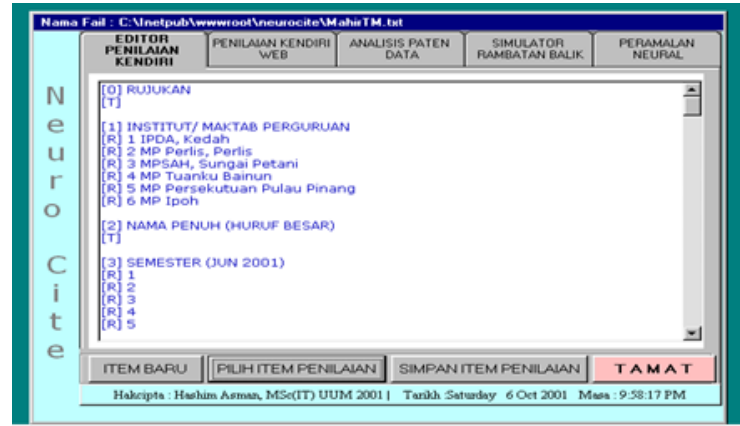

Fig 4: User Interface for Self-Evaluation Editor Module

\subsubsection{Web Self Evaluation Module}

To control the quality of the data, the respondents are required to key-in the input using web-based questionnaires. The questionnaires are uploaded from the server and the interface is shown in Figure 5. The radio buttons are used to enable the system to accept and store only the authorized data into the system's database. The stored data are preprocessed before it is sent to the next module.

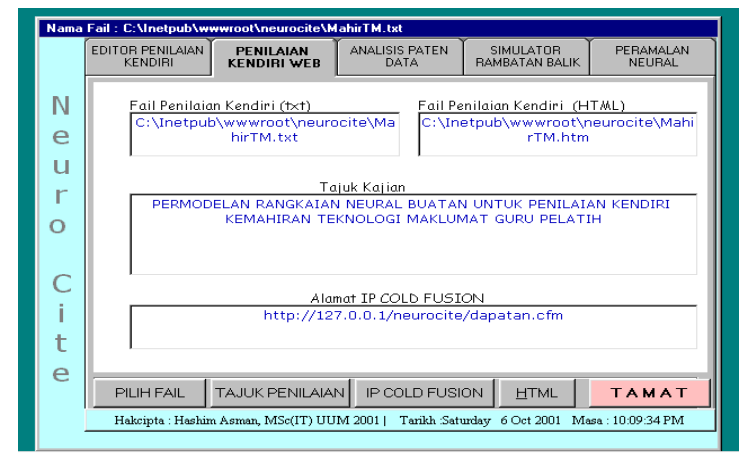

Fig 5: User Interface for Self-Evaluation Editor Module

\subsubsection{Pattern Analysis}

This module allows the administrator to set the composition of training and test sets. By default, $80 \%$ of the data are chosen randomly to represent the training patterns while the rest of them are used for testing (Figure 6). The total number of training and test patterns as well as the data distribution is displayed on the screen. All data are converted to comma separated values prior to training and testing. Basic competency in file management using the current operating system.

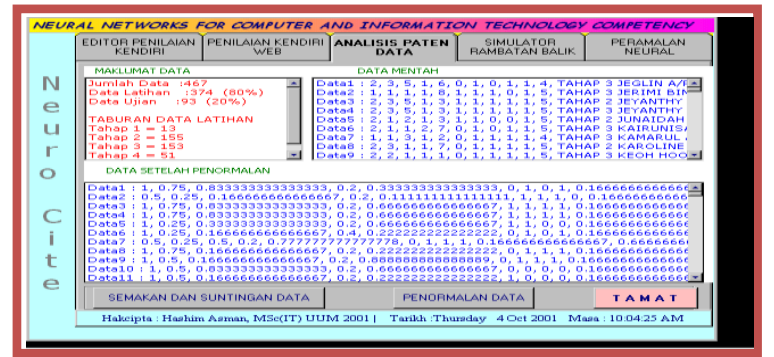

Fig 6:User Interface for Data Pattern Analysis

\subsubsection{Back Propagation Simulator}

This module allows the administrator to train and test data using backpropagation learning algorithm. NN training can be performed by adjusting training parameters such as the number of hidden unit, learning rate AND momentum rate (Figure 7).

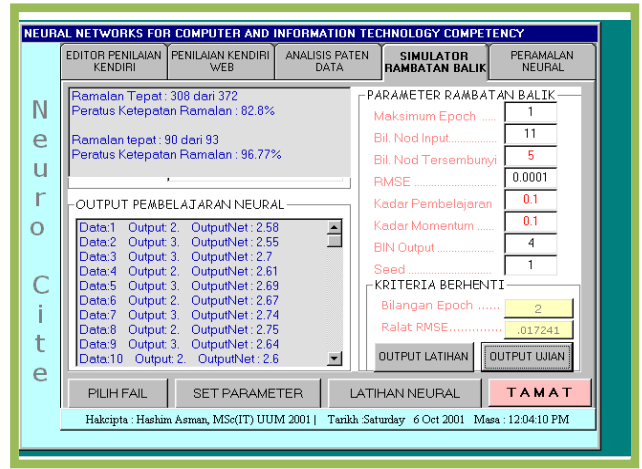

Fig 6:User Interface for Back Propagation Simulator

\subsubsection{Neural Prediction}

Once the suitable $\mathrm{NN}$ model has been acquired from the Backpropagation Simulator, the system is ready to make prediction for the new data. When the trainee enters the data using the web-based questionnaires, the system will predict the particular trainee's ITC based on the built model (Figure. $8)$.

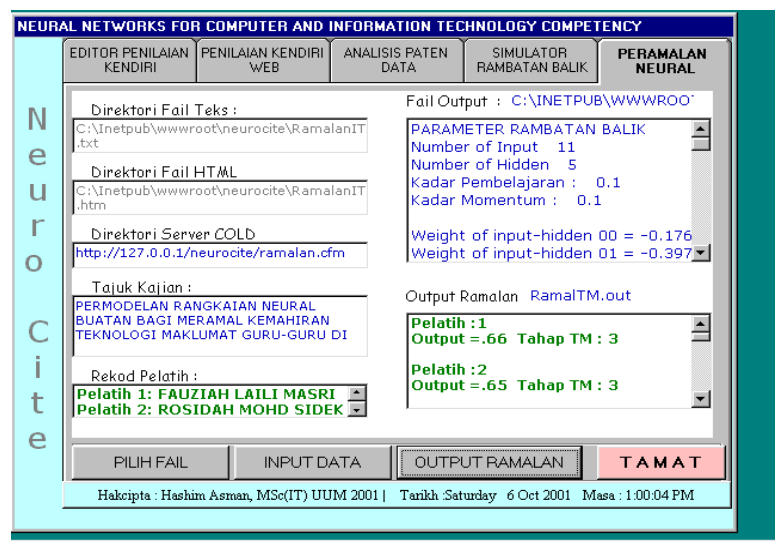

Fig 7:User Interface for Neural Prediction

\section{RESULTS}

As NeuroCite was developed for a web-based self-assessment information system, it can be used to obtain a model for predicting the ITC. The system functions as an instrument that generates questionnaires as well as performing rubric assessment online. The data are entered online, fed into NN simulator to obtain a forecasting model. Once the model is obtained, NeuroCite could be used to predict the ITC of the trainee teachers. To this end, the NN model is summarized in 
Table 3. The results indicate that the most suitable ITC forecasting model for this problem comprises of eleven input nodes, five hidden nodes and two output node. The results also exhibit that the number of epoch that provide the highest generalization with accuracy of $99.77 \%$. Hence the results show that the developed system can be used as a tool to assist decision-making in education.

For logistic purposes, the same data has been tested using nonlinear regression. The prediction model using logistic regression yields

$$
\begin{array}{cc}
\text { Predicted logjit of logistic }(\text { ITC })= & -0.0880 I_{1}-0.112 I_{2}+ \\
0.007418 I_{3}+0.164 I_{4}-0.135 I_{5}+ & 0.06503 I_{6}+ \\
0.02293 I_{7}+0.08874 I_{8}+0.08318 I_{9}+0.066 I_{10}+ \\
0.06629 I_{11}+0.538
\end{array}
$$

Table 3.NN Model for predicting Information Technology Competency among Trainee Teachers

\begin{tabular}{|l|l|}
\hline Parameter & Multilayer perceptron \\
\hline Nearning Algorithm & Backpropagation \\
\hline No. of input node & 11 \\
\hline No. of hidden units & 5 \\
\hline No. of output node & 2 \\
\hline Learning rate & 0.1 \\
\hline Momentum rate & 0.1 \\
\hline Activation Function & Sigmoid \\
\hline Stopping criteria & 500 epochs \\
\hline
\end{tabular}

The results for both $\mathrm{NN}$ and logistic regression are displayed in Table 6. The results indicate that the generalization obtained by $\mathrm{NN}$ is $9.67 \%$ higher than the one obtained by logistics regression. The results also imply that $\mathrm{NN}$ has created the potential to be integrated in education application.

Table 6.The generalization results using NN and Nonlinear Regression

\begin{tabular}{|l|l|}
\hline Approach & $\begin{array}{l}\text { Generalization } \\
(\%)\end{array}$ \\
\hline $\mathrm{NN}$ & 96.77 \\
\hline $\begin{array}{l}\text { Logistic } \\
\text { Regression }\end{array}$ & 87.10 \\
\hline
\end{tabular}

\section{CONCLUSION}

NeuroCite has been been tested and proved successful in providing the evaluation on the information technology competency online, particularly for the intranet environment. The preprocessing module that has been incorporated in Neurocite enables the model to be accomplished in a more systematic manner. Based on the results produced by NN, the system can be used as a prediction tool for education purposes. In this study, NN results outperform logistic regression. This indicates that NN have good potentials to be used as forecasting models in the future. Since research in using $\mathrm{NN}$ as forecasting tools in education is not many, future research may focuses on its use in education management as well as in teaching and learning evaluation. The use of ITC could ensure that new and existing programs do prepare quality teachers to be information technology competent in education.

\section{ACKNOLEDGEMENT}

Our thanks go to HashimAsman, who has contributed towards system development.

\section{REFERENCES}

[1] Ministry of Education, "BahagianPendidikan Guru," 2001.

[2] UNESCO, "Competency Standards Modules," 2008. [Online]. Available: Web:http://www.unesdoc.unesco.org/imases/0015/00156 2/156207e.pdf. [Accessed: 05-Oct-2012].

[3] F. Siraj, E. A. O. A. Omer, and M. R. Hasan, Data Mining and Neural Networks: The Impact of Data Representation. Croatia: Intech, 2012.

[4] F. Siraj, N. Abubakar, and M. R. Hasan, "Classification of Capital Expenditures and revenue expenditures: an Analysis of Correlation and Neural Network," in 2nd International Conference on computing and Informatics, 2009.

[5] F. Siraj and M. A. Abdoulha, "Uncovering hidden information within university's student enrollment data using data mining.," in 3rd Asia International Conference on Modelling and Simulation, 2009, pp. 413418.

[6] F. Siraj, N. Yusoff, and L. .Kee, "Emotion classification using neural network," in Proceedings of International Conference on Computing and Informatics, 2006.

[7] F. Siraj and W. R. S. Osman, "Improving generalization of neural networks using MLP discriminant based on multiple classifiers failures," Proceedings of 2 nd International Conference on Computational Intelligence, Modelling and Simulation, pp. 27-32, 2010.

[8] M. Y. ShahrulAzmi, F. Siraj, S. Yaacob, M. . P. Paulraj, and A. Nazri, "Improved Malay vowel feature extraction method based on first and second formants," 2 nd International Conference on Computational Intelligence, Modelling and Simulation, pp. 339-344, 2010.

[9] K. Li, "Application of various modeling techniques to analyze a housing condition survey dataset," in IEEE International Conference on Systems, Man and Cybernetics, 2004, pp. 409-414.

[10] S. Naik, B., \&Ragothaman, "Using neural network to predict MBA student success," College Student Journal, vol. 38, no. 1, pp. 1-4, 2004.

[11] E. N. Ogor, "Student academic performance monitoring and evaluation using data mining techniques," in Electronics, Robotics and Automotive Mechanics Conference, 2007, pp. 354-359.

[12] O. E. Oladokun, V. O., Adebanjo, A. T., \& CharlesOwaba, "Predicting students' academic performance using artificial neural network: a case study of an engineering course," The Pacific Journal of Science and Technology, vol. 6, no. 1, pp. 72-79, 2008.

[13] A. American Library Association, "Presidential Committee on Information Literacy," 1989.

[14] R. D. Westfall, "Evaluation and Assimilation Skills as Key Knowledge aspects of Information Technology Literacy," $1997 . \quad$ [Online]. Available: http://www.cyberg8t.com/westfalr/it_litrc.htm.

[Accessed: 06-Sep-2012]. 
[15] J. Young, "Learning to Learn: Assessing Information Technology Literacy," 1997.

[16] F. Siraj and M. A. Abdoulha, "Uncovering Hidden Information Within University's Student Enrollment Data Using Data Mining," MASAUM Journal of Computing, vol. 1, no. 2, pp. 337-342, 2009.

[17] F. Siraj, N. Nordin, and N. Yusoff, "Quality Function Deployment Analysis Based on Neural Network and Statistical Results. International Journal of Simulation Systems, Science \& Technology," Special Issue on: Advances in Mechatronics and AI Model, vol. 9, no. 2, pp. 73-81, 2008.

[18] F. Siraj, N. A. Bakar, and A. Abolgasim, "Classification of Capital Expenditures and Revenue Expenditures: An Analysis of Correlation and Neural Networks," Proceedings of the 2nd International Conference on Computing and Informatic, 2009.

[19] F. Siraj, N. Mustafa, M. F. Haris, S. R. M. Yusof, M. A. Salahuddin, and M. R. Hasan, "Pre-selection of Recruitment Candidates Using Case Based Reasoning," 2011 Third International Conference on Computational Intelligence, Modelling\& Simulation, pp. 84-90, Sep. 2011.

[20] F. Siraj, M. H. Yusoff, M. F. Haris, M. A. Salahuddin, S. R. M. Yusof, and M. R. Hasan, "i-SME: Loan Decision
Support System Using Neuro-CBR Approach,” 2011 Third International Conference on Computational Intelligence, Modelling\& Simulation, pp. 91-96, Sep. 2011.

[21] P. \& M. A. Linnakyla, "Profiling students on the quality of school life by neural networks," the journal Social Indicators Research, pp. 25-32, 1998.

[22] D. Katz, I. R., Williamson, D.M., Nadelman, H.L, Kirsch, I., Almond, R.G., Copper, P.L., Redman, M. L, \& Zapata, "Assesing Information and communications Technology Literacy for Higherr Education," in International Association for Educational Assessment (IAEA), 2004, pp. 13-18.

[23] J.O'Connor, L.G., Radcliff, C.J., \&Fedeon, “Assesing Information and communications Technology Literacy for Higherr Education," in Tenth National Conference of Association of College and Research Libraries, 2011, pp. 163-173.

[24] D. Descy, D. \& Johnson, "Microsoft Rubrics," 1998. [Online]. Available: http://www.ga.k12.pa.us/curtech/stucours/offrubr.htm. [Accessed: 04-Apr-2010]. 